\title{
A Study of Morbidity And Nutritional Profile Among Under Five Children in An Urban Slum, Kolkata
}

\author{
Dr. Kakali Mondal ${ }^{1}$, Dr. Sandip Baidya ${ }^{2}$, Dr. Urmila Dasgupta ${ }^{1}$ \\ ${ }^{I}$ Department Of Community Medicine, Medical College, Kolkata, India \\ ${ }^{2}$ Department Of Pharmacology, Institute Of Postgraduate Medical Education \&Research, Kolkata, India
}

\begin{abstract}
Child health is prime concern of any country. Under five age morbidity profile has a far reaching consequence on future development of country. Malnutrition is the one of the leading cause of morbidity and mortality in children of under five in developing countries The Objectives of the present study were to evaluate the morbidity profile of under-5children in urban slum in Kolkata and to identify the risk factors associated with it. It was a cross-sectional, population based, descriptive study conducted in urban slums of Rajabajar, Kolkata. Total 122 under 5 children of both sex were studied during the 3 month study period (Dec 2013-Feb 2014). Among the 122 under 5 children $54.1 \%$ was male sex. Prevalence of under-five morbidity was $52.45 \%$ among children aged 1 to 5 yrs of urban slum of Rajabazar, Kolkata. Acute respiratory infection was most common (51.56) followed by loose stool (15.62\%).Prevalence of malnutrition was $23.77 \%$. Children were mostly from lower socio-economic class (class V)- 59\%.Immunisation status was up to date among $84.4 \%$ children.
\end{abstract}

Keywords: ICD 10 code, morbidity, nutritional status, slum, under-5children

\section{Introduction}

Child health is prime concern of any country. Children are affected several times in a year. Malnutrition is the one of the leading cause of morbidity and mortality in children of under five in developing countries ${ }^{[1]}$. It is a silent killer ${ }^{[2]}$ Under five morbidity profile has a far reaching consequence on future development of country. ${ }^{[3]}$ Most of the childhood illnesses are caused by acute respiratory infections, diarrhea, measles, malaria, malnutrition or a combination of these conditions ${ }^{[4]}$ Each year 27 million children born in India. $10 \%$ of them do not survive up to 5 years. India contributes $25 \%$ of over 6.9 million under 5 death world wise every year. under5 mortality rate in 2012 was 56/1000 live birth. Infant mortality rate 41 per thousand live birth in 2012.Prevalence of morbidity is about $42 \%$ to $48 \% .{ }^{[5]}$ With this background we carried our study in an urban slum. The Objectives of our study were to evaluate the morbidity profile of under-5children in urban slum in Kolkata and to identify the risk factors associated with it.

\section{Methodology}

Our study was a cross-sectional study conducted in urban slums of Rajabajar, ward no-37, Kolkata. The study population was children aged between 1 and 5 years. Under 5 children of both sex were recruited in this study. Baseline demographic, socioeconomic, present morbidity, immunization status, nutritional status and hand hygiene were recorded. Data was captured on a predesigned structured case report form. Parents of the children were interviewed regarding socio-economic status, immunization status, nutritional status, hand hygiene and morbidity status. Clinical examination and anthropometric measurements were recorded. Growth assessment was done on the basis of the world health organization- growth chart.

\section{Results}

During the 3 month study period (Dec 2013- Feb 2014), total 122 under 5 children of both sex were studied. Among the 122 children $54.1 \%$ were males. Majority of study population $(51.60 \%)$ are of age group 13 36 months. The mean age was $30.66 \pm 16$ months. The mean length or height was $82.86 \pm 11.74 \mathrm{~cm}$. Majority of the children (59\%) belonged to class V socioeconomic class (according to BJ Prasad scale, 2013). Subjects were mostly from Muslim (88.53\%) religion. 39.3\% mothers were illiterate (Table 1), (Fig-1).

Only $29.95 \%$ mothers washed their hand before feeding their children. Immunisation status of the under five children was mostly up-to-date (84.4\%). $2.5 \%$ under five children had not taken immunisation.

Among the children $20.49 \%$ were under nutrition state. $3.28 \%$ children were severely underweight (Table -2). Children aged more than $1 \mathrm{yrs}$ and who feed less than 5 meal per day were associated with malnutrition $(\mathrm{p}=<0.001)$.But we could not found association with mother literacy and timely complimentary feeding with malnutrition.

The principal causes of morbidity in children under five years of age were acute respiratory infection, loose stool, skin infections, acute pharyngitis and dental caries. Acute respiratory infections accounted for $51.56 \%$ and loose stool accounted for $15.62 \%$. Acute pharyngitis was contributing $6.25 \%$ illness (Table -3 ). 
It was observed that prevalence of morbidity or disease was more among children having under nutrition and severely underweight(72.41\%).The nutritional status was significantly associated( $\mathrm{p}<0.05)$ with morbidity (Table -4).Mother literacy and exclusive breast feeding were not significantly associated with morbidity.

\section{Discussion}

In our study, among the 122 under five children, majority of families belonged to class $\mathrm{V}$ (59\%) socioeconomic class followed by class IV (37.7\%).A similar study by Damor Raman D. Et al ${ }^{[6]}$ reported that, majority of families $(42.89 \%)$ belonged to class IV socio-economic, followed by class-III socio-economic (28.44\%).In our present study prevalence of malnutrition was $23.77 \%$. A similar study by UPatnaik L, Pattnaik $\mathrm{S}$, Kumar V,Sahu $\mathrm{T}$ et.al ${ }^{[7]}$ observed $28.2 \%$ under nutrition among the under five children. In our study immunisation status was up to date in $84.4 \%$ of children. A study by Pervin T, Ali MH, Amin R 2005, Dhaka ${ }^{[8]}$ observed $85.8 \%$ children were completely immunised. In our present study among the 122 under five children $52.45 \%$ were morbid. A similar study by UPatnaik L, Pattnaik S, Kumar V,Sahu T et.al ${ }^{[6]}$ also reported morbidity among $48.57 \%$ under five children. During the study period, highest numbers of children were suffering from acute respiratory tract infection $(51.56 \%)$ followed by gastrointestinal tract infection. A similar study by Ujwala U. Ukey et al ${ }^{[9]}$ also observed acute respiratory tract infection (36.3\%) followed by gastrointestinal tract infection were most prevalent illness. In present study loose motion was in $15.62 \%$ children and23.77\% children were under nutrition. A study at Nagpur slum ${ }^{[10]}$ also observed in $11.39 \%$ children were suffering from loose motion and malnutrition in $52.2 \%$ under 5 children. Children aged more than $1 \mathrm{yrs}$ and who feed less than 5 meal per day were associated with malnutrition $(\mathrm{p}=<0.001)$. A similar study by Sanjana Gupta et al (2012) found similar finding. $(\mathrm{p}=0.08){ }^{[11]}$

\section{Conclusions}

Results of this study highlighted that prevalence of under-five morbidity was $52.45 \%$ among children aged 1 to 5 years of the urban slum .During the study period, highest numbers of children were suffering from acute respiratory tract infection $(51.56 \%)$ followed by gastro intestinal tract infection. In our present study prevalence of malnutrition was $23.77 \%$. Majority of children were belonged to class $\mathrm{V}$ socio-economic class (59\%) followed by class IV socio-economic (37.7\%) families. This was observed that most of the morbidities can be prevented by simple measure like adequate nutrition, hygienic practices, immunization and health education of parents. Health workers should also be trained properly. They should try to increase awareness of the community. ICDS should be involved in nutritional supplementation to the under 5 children along with the mothers and health education of the mothers.

\section{Tables and Figures}

Table 1: Baseline demographic and anthropometric data

\begin{tabular}{|l|l|}
\hline Age (months) & Mean \pm SD: $30.66 \pm 16$ \\
\hline Male sex & $54.1 \%$ \\
\hline Length/height $(\mathrm{kg})$ & Mean \pm SD: $82.86 \pm 11.74$ \\
\hline Weight $(\mathrm{kg})$ & Mean \pm SD: $10.75 \pm 2.81$ \\
\hline Muslim & $88.53 \%$ \\
\hline
\end{tabular}

Table-2. Distribution of study population according to nutritional status $(n=122)$

\begin{tabular}{|l|l|l|l|}
\hline Nutritional status & Male & Female & Total \\
\hline Normal & $50(53.77 \%)$ & $43(46.23 \%)$ & $93(76.23 \%)$ \\
\hline Under nutrition & $12(48 \%)$ & $13(52 \%)$ & $25(20.49 \%)$ \\
\hline Severely Underweight & $4(100 \%)$ & $0(0 \%)$ & $4(3.28 \%)$ \\
\hline Total & $66(54.10 \%)$ & $56(45.90 \%)$ & $122(100 \%)$ \\
\hline
\end{tabular}

Table-3. Morbidity pattern according to International Classification of Diseases $10(n=64)$

\begin{tabular}{|l|l|l|l|}
\hline Disease & ICD Code & Number & Percentage (\%) \\
\hline Acute respiratory infection & J06 & 33 & 51.56 \\
\hline Pneumonia & J15 & 3 & 4.68 \\
\hline Acute pharyngitis & J02 & 4 & 6.25 \\
\hline Acute bronchiolitis & J21 & 1 & 1.56 \\
\hline Loose stool & A08 & 10 & 15.62 \\
\hline Scabies & B86 & 4 & 7.80 \\
\hline Stye & H01 & 2 & 3.12 \\
\hline Impetigo & L01 & 2 & 3.12 \\
\hline Stomatitis & K12 & 1 & 1.56 \\
\hline ASOM & H33 & 2 & 3.12 \\
\hline Dental caries & K02 & 2 & 3.12 \\
\hline
\end{tabular}


Table- 4: Association between nutritional status and morbidity $(\mathrm{n}=122)$

\begin{tabular}{|l|l|l|l|l|}
\hline Nutritional status & \multicolumn{2}{|l|}{ Morbidity } & Total & \\
\cline { 2 - 3 } & Present & Absent & & \\
\hline Normal & $43(46.24 \%)$ & $50(53.76 \%)$ & $93(76.23 \%)$ & $\begin{array}{l}\mathrm{p}=0.019 \\
\mathrm{df}=2 \\
\mathrm{p}<0.05\end{array}$ \\
\cline { 1 - 2 } $\begin{array}{l}\text { Under nutrition and } \\
\text { Severely underweight }\end{array}$ & $21(72.41 \%)$ & $8(27.59 \%)$ & $29(23.77 \%)$ & \\
\hline Total & $64(52.45 \%)$ & $58(47.55 \%)$ & $122(100 \%)$ & \\
\hline
\end{tabular}

Fig-1. Distribution of study population according to age group in month $(\mathrm{n}=122)$

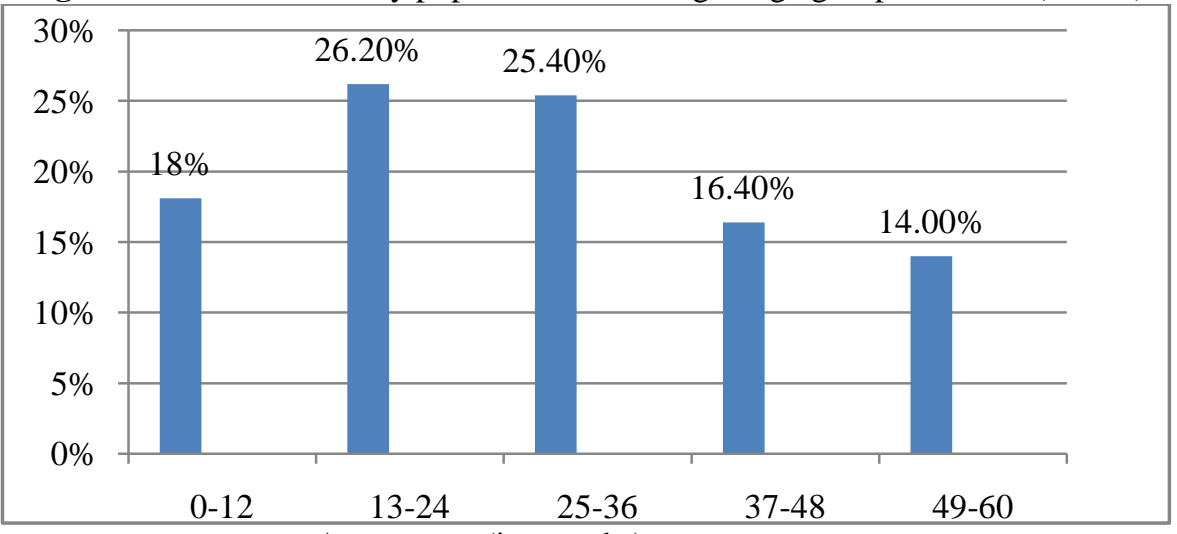

Age groups (in months)

\section{References}

[1]. D S Natekar, A Mhaske, Nutritional Status and Dietary Habits of Preschool Children,International Journal of Pharmaceutical Science Invention, 4( 9), 2015,38-42.

[2]. RD Bansal, M Mehra, Malnutrition: a silent Emergency, Indian Journal of Public Health, 43,1991, 1-2.

[3]. DK Srivastova, D Tripathy, N Gour, AK Srivastova, V Rani,Morbidity profile of under five children in urban slum of Etawah District, Indian Journal of Community Health,24(2),2012,153-157.

[4]. IMCI Information. Management of childhood illness in developing countries: Rationale for an integrated strategy,UNICEF 1999.

[5]. Park K, Park's Textbook of Preventive and Social Medicine, 22th Edition (Banarasidas Bhanot Publisher, Jabalpur, 2013 ) 509.

[6]. D R Damor, R P Pithadia, K K Lodhiya, P J Mehta , B S Yadav, A study on assessment of nutritional and immunization status of under-five children in urban slums of Jamnagar city, Gujarat. Healthline pISSN 2239-337X337X/eISSN 2320-1525,4 (2), 2013,3639.

[7]. L Patnaik, S Pattnaik, V Kumar, T Sahu, Morbidity pattern among under 5 children of in an urban slum area of Bhubaneswar City, Odisha, Indian Journal Of Maternal And Child Health,14(2),2012,1-7.

[8]. T Pervin, MH Ali, R Amin, Immunization status of under five children and its relation with antenatal care, www.oriongroup.net/journals/Journals(21),2005,262.

[9]. U Ujwala. Ukey,S Dhruv. Chitre, Morbidity Profile of Pre-School Children in an Urban Slum Area, Indian Medical Gazette,2012, 300-305.

[10]. V Narkhede, U Sinha, SD Bhardwaj, S Pitale, Morbidity Profile in Under Five Children in Urban Slum Area of Nagpur. National Journal of Community Medicine, 3(3), 2012, 442-446.

[11]. S Gupta, DS Jamwal, D Kumar, SK Gupta, Morbidity among Under Five Children in a Rural Area of Jammu, JK Science, 14(2), 2012.85-88. 